\title{
Aqueous and organic inks of carbon xerogels as models for studying the role of porosity in lithium-ion battery electrodes
}

Natalia Rey-Raap ${ }^{1}$, Marie-Laure C. Piedboeuf ${ }^{2}$, Ana Arenillas ${ }^{1 *}$, J. Angel Menéndez ${ }^{1}$, Alexandre F. Léonard ${ }^{2}$, Nathalie $\mathrm{Job}^{2}$

${ }^{1}$ Instituto Nacional del Carbón, CSIC, Apdo 73, 33080 Oviedo, Spain

2 Department of Chemical Engineering - Nanomaterials, Catalysis, Electrochemistry, Institute of Chemistry (B6a), University of Liège, B-4000 Liège, Belgium

\begin{abstract}
The electrochemical performances of lithium-ion batteries depend to a great extent on the method used to prepare the electrodes and on the pore texture of the active material. In the present study, carbon xerogels with different pore sizes and pore volumes were synthesized by means of microwave heating. These carbonaceous materials were used to prepare lithium-ion battery anodes. Generally, electrodes are prepared by coating a slurry made of an active material, a binder and N-methyl-2-pyrrolidone as organic solvent. The disadvantage of this solvent is that it is both toxic and costly. In this work, the use of water instead of the organic solvent and water-soluble binders yielded electrodes with similar electrochemical performances making the battery assembly process more economic and environmentally friendly. The results of this study also confirm that the use of an aqueous preparation pathway does not undermine the interdependence between the electrochemical properties of the cells and the porous properties of the carbon xerogels.
\end{abstract}

Keywords: lithium-ion battery, carbon gel, microwave heating, porous material

*Corresponding author. E-mail: aapuente@incar.csic.es (A. Arenillas) 


\section{Introduction}

Carbon gels are porous materials obtained by drying and carbonizing organic polymerbased gels [1]. The most interesting aspect of these materials is that their porous and chemical properties can be tailored by modifying the variables of the synthesis process to fit the requirements of a specific application [2]. For this reason, over the last decades, carbon gels have been studied in a wide range of fields including electrochemical systems such as supercapacitors and batteries [3-5]. Several works reported in the literature have demonstrated the feasibility of carbon gels to accumulate energy in supercapacitors, as well as the relationship between the electrochemical response of the systems and the porous properties of the carbonaceous material used to prepare the electrodes $[5,6]$.

The working principle of a lithium-ion battery is based on the reversible extraction of lithium ions from the cathode during the charge stage, after which they migrate through the electrolyte to intercalate into the structure of a carbon-based anode material [7-10]. During discharge, the lithium ions migrate back to the cathode [7, 9]. While intercalation of the lithium ions occurs upon charging, secondary reactions also occur, especially during the first cycle, leading to the formation of a stable passivation layer, known as the solid-electrolyte interface (SEI) [7, 8]. This reaction is irreversible and entraps the lithium ions $[11,12]$. However, this layer acts as a barrier to further degradation and its formation ensures the stability of the cell. The formation of the SEI layer and the diffusion of lithium ions through the anode material is a complex mechanism that depends largely on the chemical composition and porous properties of the active material used as anode $[7,8,13]$. 
Graphite is one of the most common carbonaceous materials employed as anode active material in lithium-ion batteries [9, 11, 14]. Nevertheless, its maximum specific capacity is limited to $372 \mathrm{mAh} / \mathrm{g}$, corresponding to 1 lithium atom for 6 carbon atoms. Moreover, changes in volume occurring during the successive insertion-deinsertion cycles can cause cell failures with long-term use $[9,11,14,15]$. Studies in which other carbons have been used show that it is possible to achieve higher capacities than that of graphite, indicating that factors other than lithium intercalation in graphitic layers also affect electrochemical performance [14, 16-18]. Indeed, it was proposed for instance that lithium can adsorb on both sides of non-stacking graphene sheets, inside micropores or on the borders of graphene layers [19-21]. Despite the numerous existing studies, the mechanisms that explain the reactions occurring inside a carbon anode of a lithium-ion cell are still unclear, although several studies have claimed that being able to control the pore texture of the carbonaceous materials is essential for improving the electrochemical performance of batteries [8, 11, 22]. Porous carbons bearing various pore textures (xerogels, cryogels, aerogels, nano- or microspheres, etc.) have been widely investigated as lithium-ion battery anodes. Ordered macroporous carbons for instance were shown to display electrochemical performances in line with those usually observed for hard carbons, but the ordered macroporous array was claimed to favour enhanced rate-performances [9]. Microporous carbons and carbon aerogels have been shown to display higher reversible capacities after increasing the micropore fraction by activation processes. Nevertheless, the enhanced capacities were also accompanied by increased irreversible losses during the first insertion-deinsertion cycle [22, 23]. Unmodified carbon aerogels and xerogels were also evaluated as anode materials, with reversible capacities ranging from 380 to $500 \mathrm{mAh.g}{ }^{-1}$, but in each case with considerable irreversible losses [14]. In all of these studies, it can be highlighted that 
enhanced reversible capacities are mostly accompanied by increased irreversible losses. Moreover, the reversible and irreversible capacities can sometimes be very different from one study to the other, even for materials displaying similar pore textures. Consequently, carbon xerogels might be considered as good candidates as model materials for studying the electrochemical behaviour of porous carbons in general, since as explained above, their porous properties can be controlled and designed by choosing the appropriate synthesis conditions [1, 2, 24]. In addition, carbon gels can be produced by means of a fast, easy and cheap synthesis process based on microwave radiation, which yields most cost-competitive and high value-added active materials [1].

For assembling an electrochemical cell, the active material needs to be mixed with a solvent and a binder in order to obtain a homogenous mixture for coating on the current collectors. The fluidity of the mixture will depend on the casting method employed (i.e., by hand, doctor-blade or spray). These mixtures are referred to in the literature as slurry or ink. The most frequent method for preparing inks or slurries involves the use of polyvinylidene fluoride (PVDF) as binder and N-methyl-2-pyrrolidone (NMP) as solvent [12, 25-30]. This solvent is expensive, toxic and flammable [12]. Therefore, the use of an economical and more environmentally friendly solvent such as water is necessary to make batteries more cost-effective. Some authors have succeeded in replacing organic solvents with water when preparing electrodes from $\mathrm{LiFePO}_{4}$ [26] or carbon black [31]. However, to the best of our knowledge, no study has been published to date on the use of water for preparing electrodes when carbon xerogels are employed as electrode material. 
Thus, the present work aims to take a step further towards the understanding of porous carbons behaviour as electrode material in lithium-ion batteries via a more economical and environmentally friendly route. Hence, the first purpose of this study is to use carbon xerogels synthesized by microwave heating and with different porous properties as active material in lithium-ion batteries in order to determine the relationship between the porous properties of carbon materials and the electrochemical capacity of the systems. This study will complete the previous one performed on carbon xerogels obtained by the conventional method based on sol-gel, ageing and dying by evaporation [4], in order to check whether the manufacture process may influence the electrochemical behaviour. Second, carbon xerogel-based electrodes were prepared by replacing the solvent (NMP with water) and the binder (PVDF by sodium carboxymethyl cellulose [Na-CMC] and styrene butadiene rubber [SBR]). The effectiveness of using water instead of NMP and different types of binder is evaluated by analysing the electrochemical behaviour of the cells.

\section{Experimental}

\subsection{Microwave-assisted synthesis of organic xerogels}

Organic xerogels were synthesized by the polycondensation of resorcinol (R) and formaldehyde (F) using deionized water as solvent and sodium hydroxide as basification agent. The resorcinol (Indspec, 99\%) was first dissolved in the deionized water in an unsealed glass beaker under magnetic stirring. After dissolution, the formaldehyde (Merck, 37 wt.\% in water, stabilized by 10-15\% methanol) was added and the resulting mixture was stirred until a homogeneous solution was obtained. Finally, the $\mathrm{pH}$ of the precursor solution was finely adjusted to the chosen value. To this aim, and so as not to modify significantly the dilution ratio, two different $\mathrm{NaOH}$ 
solutions were used: a $5 \mathrm{M}$ solution prepared from solid $\mathrm{NaOH}$ (AnalaR Normapur, 99.9\%) and a commercial 0.1 M solution (Titripac from Merck). The concentrated solution was added dropwise until the $\mathrm{pH}$ was close to the target, then the diluted solution was used to precisely adjust the $\mathrm{pH}$. The concentration of each reagent (resorcinol, formaldehyde, water and $\mathrm{NaOH}$ ) was selected on the basis of the results reported in a previous published work in order to obtain materials of different pore sizes [2]. Accordingly, the precursor solutions were prepared with $\mathrm{pH}$ values ranging between 4 and 6, dilution ratios (i.e. water/reagents molar ratio) between 5 and 9 and R/F molar ratios ranging from 0.5 to 0.3 .

All the organic gels were synthesized from $200 \mathrm{~mL}$ of precursor solution. The solution was poured into an unsealed glass beaker (transparent to microwaves) which was then placed in a multimode microwave oven (in-lab design and construction [32]) at $85{ }^{\circ} \mathrm{C}$ for $3 \mathrm{~h}$, to allow gelation and ageing to be completed. After the formation of the polymeric structure, any excess water was eliminated by further heating of the gel in the microwave oven until a constant mass was achieved. The drying step lasted from 1 to 2 $\mathrm{h}$ depending on the final porous texture of the material. All the samples were ground prior to carbonization using a mixer mill (Retsch MM400) at $300 \mathrm{rpm}$ during $60 \mathrm{~min}$. The particle size distribution of the powders was obtained by means of laser diffraction analysis using a Mastersizer 2000 (Malvern Instruments) in wet mode (Hydro2000) in order to ensure that the particle size was centred at ca. $10 \mu \mathrm{m}$ (see Supporting Information for more experimental details; the particle size distributions of the organic xerogels are shown in Figure S1a).

\subsection{Synthesis of carbon xerogels}


The organic gel powders were carbonized at $700{ }^{\circ} \mathrm{C}$ under a nitrogen flow in a horizontal tubular furnace. The carbonization process was performed in three successive steps: (i) heating up to $150^{\circ} \mathrm{C}$ at $1.7^{\circ} \mathrm{C} / \mathrm{min}$, (ii) heating up to $400^{\circ} \mathrm{C}$ at $5^{\circ} \mathrm{C} / \mathrm{min}$ and (iii) heating up to $700^{\circ} \mathrm{C}$ at $5^{\circ} \mathrm{C} / \mathrm{min}$. The residence time for each step was 15,60 and 120 min, respectively. After the last step, samples were left to cool down to room temperature. The particle size distribution of the carbon xerogel powders was also determined prior to the preparation of the inks (see Supporting Information for more experimental details: the particle size distributions of the carbon xerogels are shown in Figure S1b). The carbon xerogels obtained are labelled CX followed by the value of the average pore size (in nm), obtained by means of mercury porosimetry (see section 2.4). For instance, sample CX-50 is a carbon xerogel with an average pore size of around 50 $\mathrm{nm}$.

\subsection{Preparation of organic and aqueous inks}

The organic inks (labelled 'OI') were prepared by mixing under magnetic stirring 92 wt. $\%$ of carbon xerogel, 8 wt. \% of polyvinylidene fluoride (PVDF, binder supplied by Alfa Aesar) and N-methyl-2-pyrrolidone (NMP, Alfa Aesar) to form a homogeneous slurry, whereas the aqueous inks (labelled 'AI') were prepared by mixing 92 wt. \% of carbon xerogel, 4 wt. \% of sodium carboxymethyl cellulose (Na-CMC, binder Walocel CRT 2000 PA kindly supplied by Dow Wolff Cellulosics GMBH), 4 wt. \% of styrene butadiene copolymer (SBR, binder supplied by MTI Corporation) and deionized water.

\subsection{Electrode and cell preparation}

Each ink was sprayed onto pre-weighed stainless steel disks of diameter $15.5 \mathrm{~mm}$ (electrodes), and onto stainless steel rectangular strips of $1 \times 5 \mathrm{~cm}$. The coating was 
performed using a Harder \& Steenbeck Evolution Silverline 2 airbrush. After the coating, the electrodes were dried at ambient temperature for $2 \mathrm{~h}$ and afterwards at $60^{\circ} \mathrm{C}$ overnight. The thickness of the dried coating was measured on the strips by stylus profilometry (Veeco Dektak 150, stylus radius: $12.5 \mu \mathrm{m}$, force: $2.00 \mathrm{mg}$ ), with the carbon being scratched off at regular intervals to establish a baseline. The thickness was obtained as an average value taken from two different strips and applying three scans to each strip. The coated disk-electrodes were weighed to calculate the mass of the active material prior to their electrochemical characterization. Half-cells were then assembled in CR2032 coin cells, in which the carbon xerogels acted as the positive electrode and a Li-metal disk (MTI Corporation) served as the negative- and reference electrode. The insertion of Li ions inside the carbon structure corresponds to a discharge, whereas the deinsertion corresponds to a charge. This setup is opposite to that of a full-cell, where the carbon would be a negative electrode and a metallic oxide, such as $\mathrm{LiCoO}_{2}$ for instance, would be the positive electrode. Two porous polyethylene separators (Celgard $^{\circledR}, 25 \mu \mathrm{m}$ thickness, MTI Corporation) soaked with $80 \mu \mathrm{L}$ of electrolyte (1 M $\mathrm{LiPF}_{6}$ in Ethylene carbonate : Diethylene carbonate : Dimethyl carbonate 1:1:1, Selectilyte LP71 Merck) were placed in-between. The half-cells were assembled in a glove-box filled with Argon (MBraun).

The excess dried coating from the spraying process was collected from the support as a powder (binder-active material composite) in order to characterize the material present on the electrodes. The composites resulting from the drying of the organic and aqueous inks were labelled 'OIC' (for 'Organic Ink Composite') and 'AIC' (for 'Aqueous Ink Composite'), respectively.

\subsection{Sample characterization}




\subsubsection{Pore texture}

The pore size distribution of the carbon xerogels was measured by means of mercury porosimetry (ThermoScientific Pascal 140 and 240). Measurements were performed between 0.01 and $200 \mathrm{MPa}$. The mercury intrusion data obtained were analysed to determine the distribution of pores larger than $7.5 \mathrm{~nm}$ in diameter, calculated by using the Washburn equation [24].

The carbon xerogels as well as the binder-active material composites (series CX, OIC and AIC) were characterized by performing nitrogen adsorption-desorption isotherm analysis at $-196{ }^{\circ} \mathrm{C}$ on a Micromeritics ASAP 2420 instrument. Prior to taking the measurements, the samples were degassed overnight at $270^{\circ} \mathrm{C}$ under high vacuum $(133$ $\mathrm{Pa}$ ). The total specific surface area (BET surface area, $\mathrm{S}_{\mathrm{BET}}$ ) was calculated by applying the Brunauer-Emmett-Teller theory to the adsorption data obtained in the relative pressure range of 0.01 to 0.10 [33]. The external surface area $\left(\mathrm{S}_{\text {ext }}\right)$, i.e. the surface corresponding to the meso-macropores, was determined following the t-plot method [34]. Since carbon xerogels can be described as a stacking-up of microporous spherelike nodules delimiting meso-macroporous voids [24], this surface corresponds to the external area of the nodules. Finally, the micropore volume $\left(V_{D U B}\right.$, volume of pores of width lower than $2 \mathrm{~nm}$ ) was determined by the Dubinin-Radushkevich method [35].

\subsubsection{Electrochemical measurements}

Electrochemical measurements were applied to the CR2032 coin cells. At least two cells of each material were tested in identical conditions in order to ensure repeatability of the results. Charge-discharge curves were recorded at C/5 between 0.005 and $1.5 \mathrm{~V}$ (vs. $\mathrm{Li}^{+} / \mathrm{Li}$ ) using a Biologic VMP3 multichannel potentiostat, inside a climate chamber at 
$25^{\circ} \mathrm{C}$. Cyclic voltammetry was also performed over the same potential range at a scan rate of $0.1 \mathrm{mV} / \mathrm{s}$.

\section{Results and discussion}

\subsection{Pore texture of the carbon xerogels}

The $\mathrm{N}_{2}$ adsorption-desorption isotherms of the synthesized carbon xerogels are displayed in Figure 1a. All the samples present similar volumes of nitrogen adsorbed at low relative pressures, indicating that they all have a similar specific surface area $\left(\mathrm{S}_{\mathrm{BET}}\right.$ ranging from 620 to $688 \mathrm{~m}^{2} / \mathrm{g}$ ) and a similar micropore volume ( $\mathrm{V}_{\text {DUB }}$ ca. $\left.0.26 \mathrm{~cm}^{3} / \mathrm{g}\right)$. However, there are striking differences between their porous properties resulting from the composition of the precursor solution. These differences are of great importance for the evaluation of the electrochemical performance of the cells. Sample CX-8 shows a combined isotherm of type I and type IV with a marked hysteresis loop at high relative pressure, characteristic of micro-mesoporous materials. When the composition of the precursor solution is modified, the hysteresis loop shifts to higher pressures due to the presence of large mesopores, which agrees with the pore size distribution in Figure 1b recorded by means of mercury porosimetry. Thus, the carbon xerogels evolve from micro-mesoporous to micro-macroporous materials (with each xerogel, CX-8, CX-20, CX-50, CX-130 and CX-200, presenting an average pore size of 8, 20, 50, 130 and 200 $\mathrm{nm}$ respectively). 

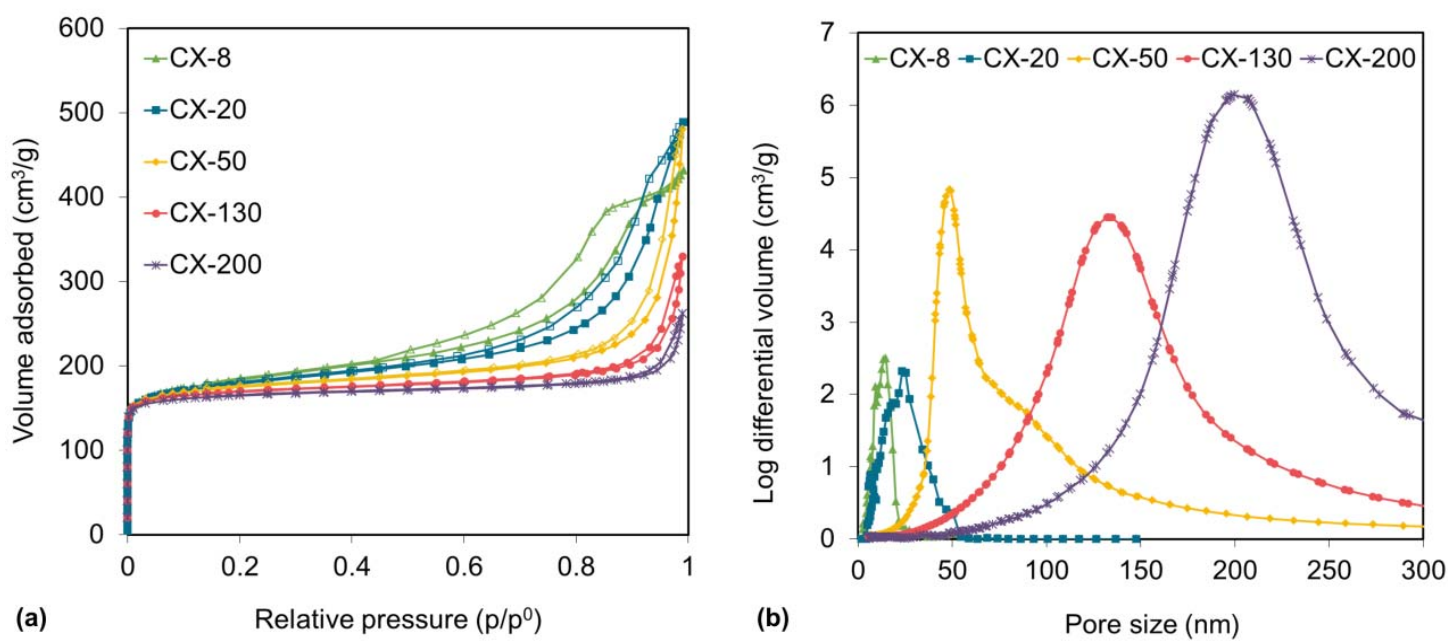

Figure 1. (a) $\mathrm{N}_{2}$ adsorption-desorption isotherms and (b) pore size distributions taken from $\mathrm{Hg}$ intrusion porosimetry measurements of the carbon xerogels.

\subsection{Pore texture of the active material-binder composites}

The $\mathrm{N}_{2}$ adsorption-desorption isotherms for the active material-binder composites obtained from the coating of the organic inks (OIC) and the aqueous inks (AIC) are presented in Figure $\mathrm{S} 2$ in the Supporting Information. The external $\left(\mathrm{S}_{\text {ext }}\right)$ and BET $\left(\mathrm{S}_{\mathrm{BET}}\right)$ surface areas were calculated from the isotherm data and are plotted in Figure 2.
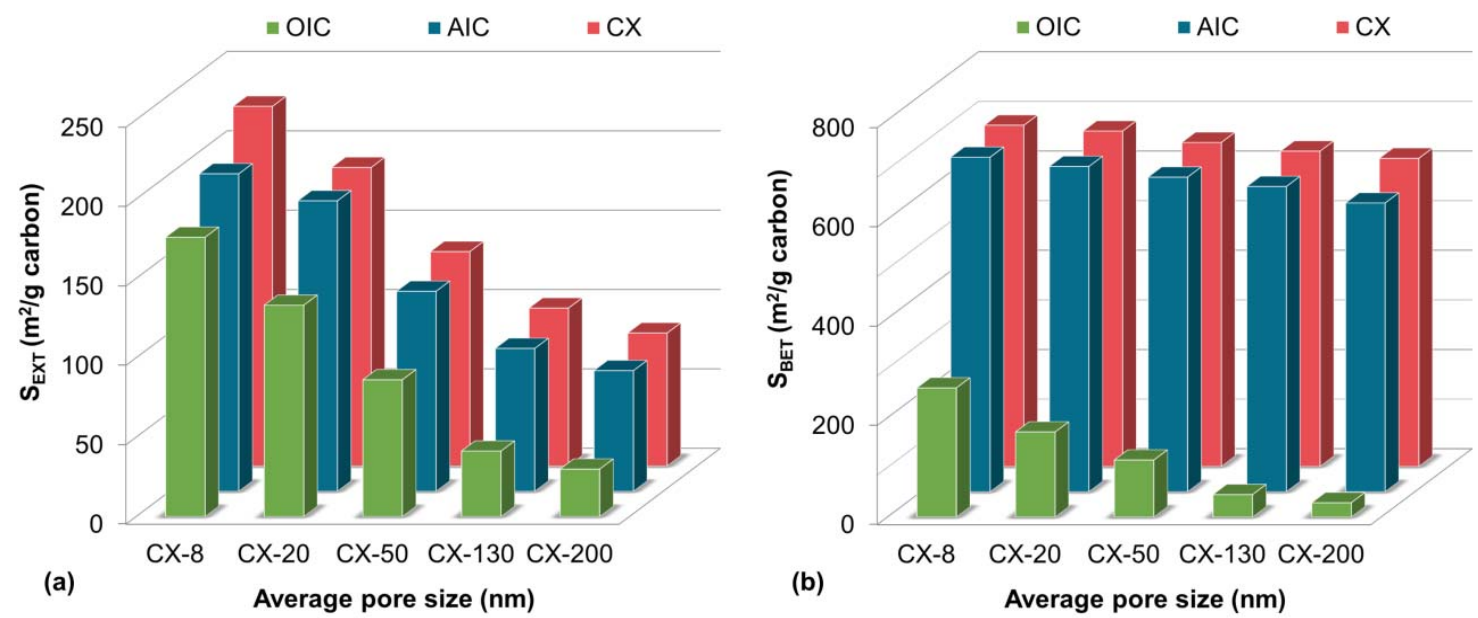

Figure 2. (a) External surface area $\left(\mathrm{S}_{\mathrm{ext}}\right)$ and (b) BET surface area $\left(\mathrm{S}_{\mathrm{BET}}\right)$ of the synthesized carbon xerogels (CX) and the corresponding organic solvent-based (OIC) and water-based (AIC) composites. 
The external surface area $\left(\mathrm{S}_{\mathrm{ext}}\right)$ of the carbon xerogels, i.e. the surface corresponding to the meso- or macropores, decreases from 227 to $84 \mathrm{~m}^{2} / \mathrm{g}$ as the pore sizes increases (see Table S1 in the supporting information). Indeed, this surface corresponds to the external area of the nodules that make up the carbon xerogel structure. The same trend is observed in the case of the composites, though the values are lower than those of the corresponding carbon xerogels, due to the incorporation of binder in the pore texture. The composites resulting from the drying of the organic solvent (OIC) and aqueous (AIC) inks show differences in $\mathrm{S}_{\text {ext }}$ values despite the fact that both types of ink were prepared with the same amount of binder (8 wt.\%). In the case of OIC, the external surface is significantly reduced in comparison with that corresponding to the bare xerogel, whereas the reduction is much less pronounced in the case of the AIC. These differences are probably due to the fact that during the preparation of the organic solvent inks the binder penetrates more deeply into the innermost parts of the material than in the case of the aqueous inks, presumably due to the less hydrophilic nature of the carbon. These data are in agreement with the values of BET surface area $\left(\mathrm{S}_{\mathrm{BET}}\right)$ displayed in Figure 2b. Indeed, the organic solvent-based composites (OIC) exhibit much lower $\mathrm{S}_{\mathrm{BET}}$ values than their aqueous counterparts (AIC), even though the same amount of binder is used. This may be due to the fact that the binder penetrates more deeply during the preparation of the organic solvent inks, blocking access to the micropores and so, provoking a sharp decrease in the BET surface area.

In this study, different types of binder were used to prepare the inks, depending on the type of solvent (NMP or water). Hence, the differences in the extent of penetration by the binder inside the carbon structure must be due either to the type of solvent or the 
type of binder used. In order to determine which of these factors was responsible for the change, a new ink was prepared by mixing the CX-200 carbon xerogel, CMC and SBR (binder mixture used to prepare the aqueous inks and which is also soluble in NMP) and NMP (solvent used to prepare the organic inks). The resulting composite after the drying of the mixed ink was labelled 'MIC’ ('Mixed Ink-based Composite').

The nitrogen adsorption-desorption isotherms of the CX-200 carbon xerogel and the corresponding active material-binder composites, obtained from the coating of the organic ink (OIC), aqueous ink (AIC) and mixed ink (MIC), are shown in Figure 3a, and the values of the external surface areas, $\mathrm{S}_{\mathrm{ext}}$, are presented in Figure 3b.
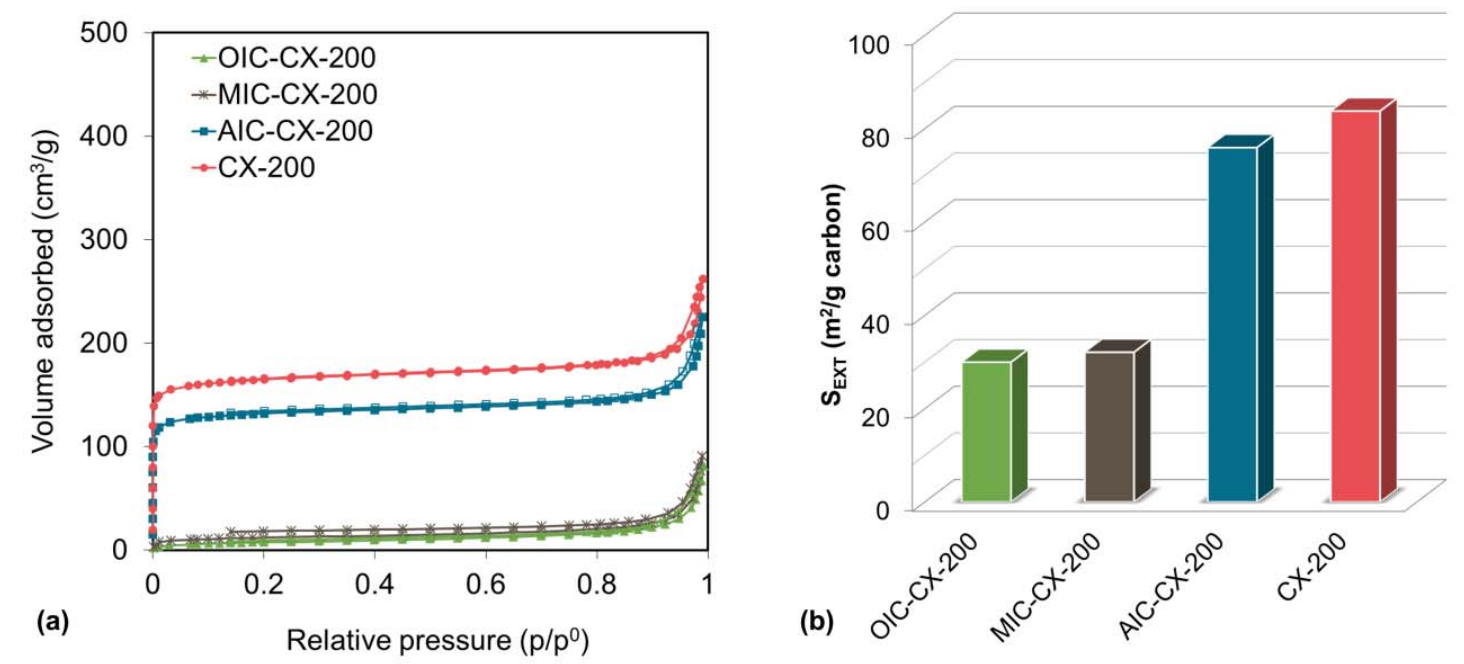

Figure 3. (a) Nitrogen adsorption-desorption isotherms and (b) external surface area values ( $\mathrm{S}_{\mathrm{ext}}$ ) of the CX-200 carbon xerogel and its corresponding organic-based (OIC), mixed-based (MIC) and water-based (AIC) composites.

The $\mathrm{N}_{2}$ adsorption-desorption isotherms of the three types of active material-binder composites and the carbon xerogel display the same shape at high relative pressure, suggesting that no changes occurred in the large pore region. Confirmation was not performed by mercury porosimetry due to the difficulties involved in applying this 
technique to active material-binder composites. A comparison of the isotherms at low relative pressure indicates that sample MIC-CX-200 has a low adsorbed volume similar to that of sample OIC-CX-200. In agreement with these data, samples MIC-CX-200 and OIC-CX-200 also exhibit similar $\mathrm{S}_{\text {ext }}$ values (Figure 3b). From this observation, it can be concluded that, in this case, the solvent is the chief factor influencing blockage of the microporosity by the binder. In other words, NMP allows the binder to penetrate more deeply into the pore texture of porous carbons than water. This is probably due to the chemical surface composition of the carbons which shows a greater affinity for organic solvents than for aqueous solvents, resulting in a better surface wettability. However, to explain the behaviour of carbon xerogels as anode materials as a function of their pore texture, the aqueous pathway (water-CMC system) would seem to be more appropriate than the organic pathway (NMP-PVDF system), since the electrodes should display similar textural properties to those of the initial carbon.

\subsection{Electrochemical properties}

The electrodes prepared from carbon xerogels with different pore textures and different types of inks were used to evaluate the behaviour of carbon xerogel-based electrodes for $\mathrm{Li}$ insertion-deinsertion. The thickness of the final electrodes, evaluated by profilometry, ranged from 10 to $15 \mu \mathrm{m}$. Their electrochemical performances were determined taking into consideration that the insertion of lithium into the carbon structure occurs during the discharge of the cell, whereas extraction of lithium occurs while the cell is being charged, due to the half-cell configuration. The galvanostatic charge-discharge technique was employed to evaluate the influence of the pore texture of five carbon xerogels. For that purpose, the carbons were employed as active material in electrodes prepared with organic solvent (series OIC) and aqueous (series AIC) based 
inks. The charge-discharge curves corresponding to the different half-cells during the $1^{\text {st }}$ cycle are shown in Figure 4. The curves were obtained at a rate of C/5 (i.e. the current necessary to charge the battery completely in $5 \mathrm{~h}$, assuming a theoretical value for graphite of $372 \mathrm{mAh} / \mathrm{g}$ ). The charge-discharge curves recorded for the different halfcells in the $40^{\text {th }}$ cycle are presented in Figure $4 \mathrm{c}$ and $4 \mathrm{~d}$.
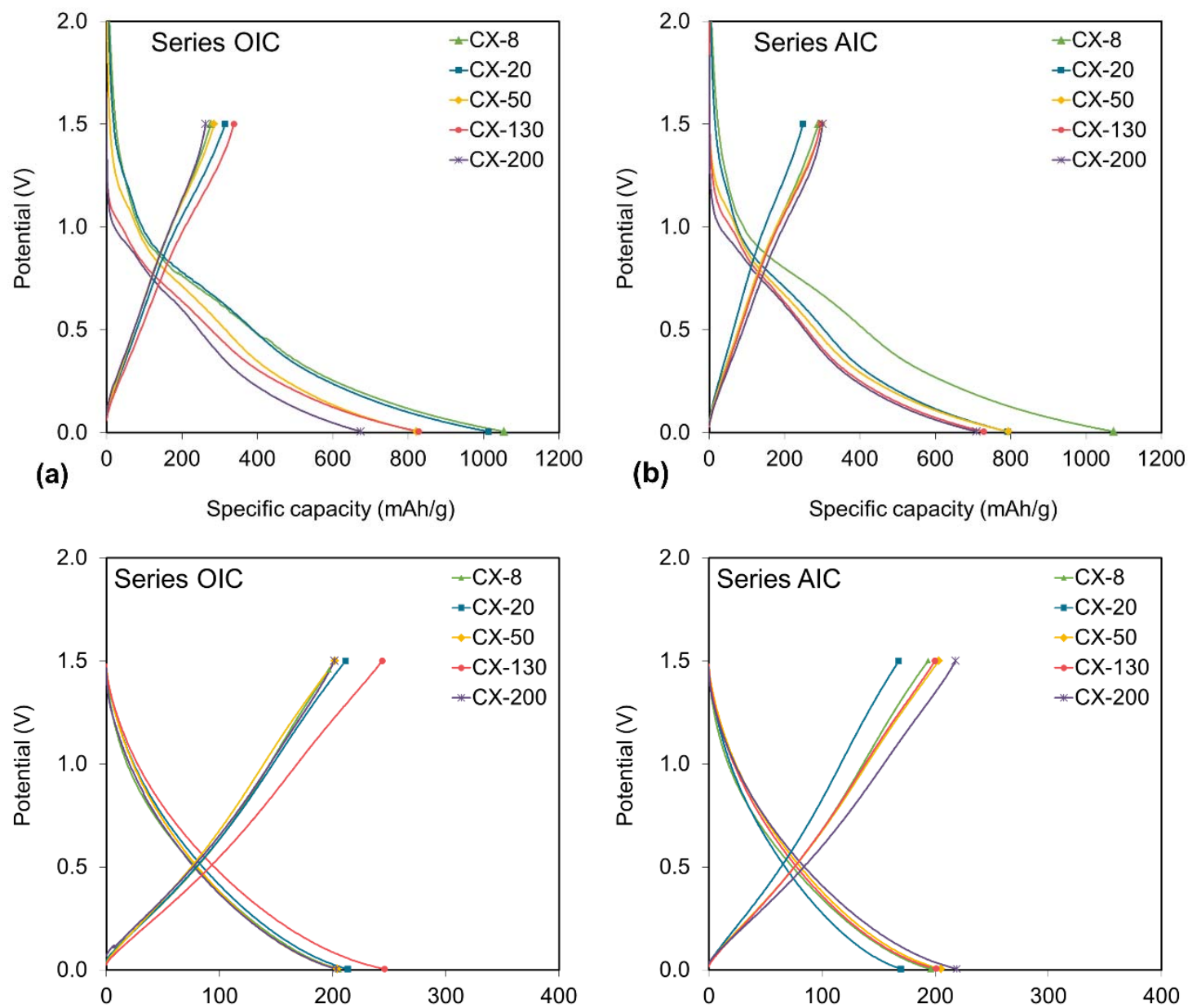

(c)

Specific capacity $(\mathrm{mAh} / \mathrm{g})$



(d)

Specific capacity $(\mathrm{mAh} / \mathrm{g})$

Figure 4. Charge-discharge curves at a $\mathrm{C} / 5$ rate for the $1^{\text {st }}$ cycle of carbon xerogels of different pore size ( $\mathrm{a}$ and $\mathrm{b}$ ) and the $40^{\text {th }}$ cycle (c and d); the electrodes were prepared from organic inks (a and c) and aqueous inks (b and d).

The charge-discharge curves of the anode materials prepared from organic (series OIC) and aqueous (series AIC) inks exhibit a similar electrochemical behaviour. In agreement 
with data published on the use of carbons as electrode material $[9,22,27,28]$, the curves shown in Figure 4 do not exhibit a voltage plateau corresponding to the insertion-deinsertion of lithium, but rather a gradual decay in the voltage.

The calculated values of the capacities resulting from the galvanostatic cycling of the different half-cells are presented in Table 1. It should be noted that, generally, an increase in reversibility is accompanied by a decrease in irreversible losses during the first charge-discharge cycle, which makes the comparison of these data difficult. In order to obtain a better insight into the behaviour of carbon xerogels as anode materials, more pertinent information can be gained from the relative irreversible losses, that can be expressed by the ratio between irreversible and reversible capacity ( $\left.\mathrm{Q}_{\mathrm{irr}} / \mathrm{Q}_{\mathrm{rev}}\right)$. In the present study, this ratio was employed for all the half-cell assemblies and their associated numerical values are presented in Table 1 along with the more noteworthy textural properties of the initial carbon xerogels that were used as active material.

Table 1. Textural properties and electrochemical parameters.

\begin{tabular}{|c|c|c|c|c|c|c|c|c|}
\hline \multicolumn{3}{|c|}{ Carbon xerogels } & \multicolumn{3}{|c|}{ Series OIC } & \multicolumn{3}{|c|}{ Series AIC } \\
\hline Sample & $\begin{array}{l}\mathrm{S}_{\mathrm{BET}}^{\mathrm{a}} \\
\left(\mathrm{m}^{2} / \mathrm{g}\right)\end{array}$ & $\begin{array}{l}\mathrm{S}_{\text {ext }}^{\mathrm{b}} \\
\left(\mathrm{m}^{2} / \mathrm{g}\right)\end{array}$ & $\begin{array}{l}\mathrm{Q}_{\text {irr }}^{\mathrm{c}} \\
(\mathrm{mAh} / \mathrm{g})\end{array}$ & $\begin{array}{l}\mathrm{Q}_{\text {rev }}{ }^{\mathrm{d}} \\
(\mathrm{mAh} / \mathrm{g}\end{array}$ & $\mathrm{Q}_{\text {irr }} / \mathrm{Q}_{\mathrm{rev}}{ }^{\mathrm{e}}$ & $\begin{array}{l}\mathrm{Q}_{\text {irr }}^{\mathrm{c}} \\
(\mathrm{mAh} / \mathrm{g})\end{array}$ & $\begin{array}{l}\mathrm{Q}_{\text {rev }}{ }^{\mathrm{d}} \\
(\mathrm{mAh} / \mathrm{g}\end{array}$ & $\mathrm{Q}_{\mathrm{irr}} / \mathrm{Q}_{\mathrm{rev}}^{\mathrm{e}}$ \\
\hline CX-8 & 688 & 227 & 778 & 276 & 2.8 & 784 & 290 & 2.7 \\
\hline CX-20 & 676 & 188 & 699 & 314 & 2.2 & 542 & 249 & 2.2 \\
\hline CX-50 & 653 & 135 & 537 & 285 & 1.9 & 495 & 298 & 1.7 \\
\hline CX-130 & 636 & 99 & 491 & 337 & 1.5 & 432 & 296 & 1.5 \\
\hline CX-200 & 621 & 84 & 358 & 262 & 1.4 & 408 & 301 & 1.4 \\
\hline
\end{tabular}

${ }^{\mathrm{a}}$ Calculated in the $\mathrm{P} / \mathrm{P}_{0}$ range of $0.01-0.10$ with an accuracy of $\pm 5 \%$.

${ }^{\mathrm{b}}$ Calculated by the t-plot method with an accuracy of $\pm 5 \%$.

${ }^{\mathrm{c}}$ Irreversible capacity in the first cycle of charge-discharge calculated by subtraction of the first charge capacity from the first discharge capacity.

${ }^{\mathrm{d}}$ Reversible capacity corresponding to the charge capacity of the half cell.

${ }^{\mathrm{e}}$ Ratio between the irreversible and reversible capacity in the $1^{\text {st }}$ charge-discharge cycle. 
No clear tendency is observed for reversible capacity $\left(\mathrm{Q}_{\mathrm{rev}}\right)$, with values remaining in the same range (ca. $300 \mathrm{mAh} / \mathrm{g}$ ) for all the tested samples. The values stayed in the same range upon cycling up to 40 cycles, with no further irreversible losses. On the other hand, the irreversible capacity $\left(Q_{\text {irr }}\right)$ tends to decrease with increasing pore size. However, these absolute values have to be treated with care, in view of the degree of uncertainty surrounding the mass of active material. For that reason, the $\mathrm{Q}_{\text {irr }} / \mathrm{Q}_{\mathrm{rev}}$ ratio is much more reliable. The $\mathrm{Q}_{\text {irr }} / \mathrm{Q}_{\text {rev }}$ ratio decreases as the pore size increases. Since the reversible capacities of all of the carbon xerogels are in the same range, the lower $\mathrm{Q}_{\text {irr }} / \mathrm{Q}_{\text {rev }}$ ratio due to the larger pore size can be ascribed to lower irreversible losses during the first charge-discharge cycle [12]. The lowest irreversible losses for the electrode with the carbon xerogels of large pore size can be attributed to its smallest external surface area, $\mathrm{S}_{\text {ext }}$, corresponding to the surface of the carbon nodule. Indeed, the $\mathrm{S}_{\mathrm{BET}}$ of the carbon xerogels studied in the present work are all in the same range as shown in Table 1, indicating that there is no relationship between this parameter and the electrochemical behaviour, which is in accordance with data published by Béguin et al. and Piedboeuf et al. [4, 13].

Figure 5 shows the evolution of the $\mathrm{Q}_{\text {irr }} / \mathrm{Q}_{\text {rev }}$ ratio as a function of the external surface area of the carbon xerogels used as active material in the electrodes prepared from organic and aqueous inks. A very clear relationship can be observed between the $S_{\text {ext }}$ and the $\mathrm{Q}_{\text {irr }} / \mathrm{Q}_{\mathrm{rev}}$ ratio for all samples. From Figure 5 it can also be seen that the relationship between the $\mathrm{Q}_{\text {irr }} / \mathrm{Q}_{\text {rev }}$ ratio and the $\mathrm{S}_{\text {ext }}$ is maintained in all the electrodes prepared with organic solvent and aqueous inks. 


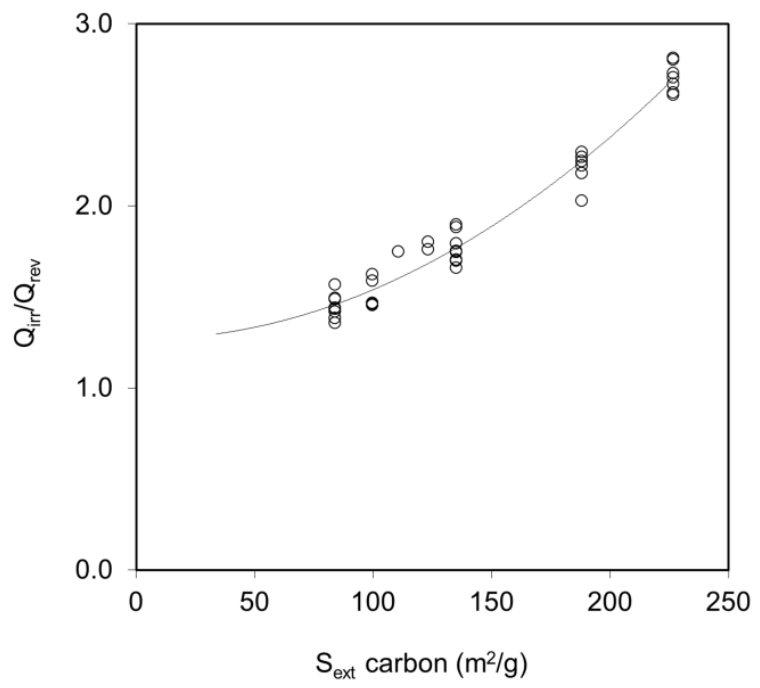

Figure 5. Irreversible-reversible capacity ratio $\left(\mathrm{Q}_{\mathrm{irr}} / \mathrm{Q}_{\mathrm{rev}}\right)$ as a function of the external surface area of carbon xerogels.

No differences in $\mathrm{Q}_{\text {irr }} / \mathrm{Q}_{\text {rev }}$ ratio can be appreciated when comparing organic solventbased and aqueous-based electrodes prepared from the same carbon xerogel. Therefore, it can be concluded that, for the materials studied, the replacement of the NMP-PVDF system by the water-CMC/SBR system to obtain carbon xerogel-based electrodes is a viable process which avoids the use of a toxic compound without causing any significant deterioration in electrochemical behaviour when they are employed as anodes in lithium-ion batteries.

\section{Conclusions}

The electrochemical capacities obtained when using water as solvent and a mixture of CMC and SBR as binder (aqueous ink), were similar to those obtained in the electrodes prepared from organic inks, regardless of the porosity of the carbons studied. Thus, the NMP-PVDF system, which is commonly employed to prepare carbon-based electrodes, could be replaced with a water-CMC/SBR system in order to make way for a more 
environmentally friendly process without any change of electrochemical behaviour in porous carbon based anode materials.

It was also found a relationship between the electrochemical properties and the external surface area $S_{\text {ext }}$ of the carbon xerogels used. However, no relationship was observed between the total specific surface area, $\mathrm{S}_{\mathrm{BET}}$, and electrochemical behaviour, whichever solvent-binder pair was used. Therefore, the role of micropores in the electrochemical behaviour in batteries is doubtful, and the research should be focused in the production of carbons with good electrical conductivity but also with wide pores and low external surface area in order to minimize the irreversible capacity.

Although the absolute values of capacities remain lower than those obtained when using commercial graphite, the use of carbon xerogels processed into aqueous- or organic based inks can help in understanding the electrochemical behavior of porous hard carbons.

\section{Acknowledgements}

Financial support from the Ministerio de Economía y Competitividad of Spain (MINECO) under Projects MAT2011-23733, IPT-2012-0689-420000 and CTQ2013 49433-EXP is greatly acknowledged. N.R.R is also grateful to MINECO for her predoctoral research grant. M.-L. P. thanks the F.R.S.-FNRS for a FRIA fellowship grant. A. L. acknowledges the financial support received from the Région Wallonne (BATWAL Convention 1318146, PE Plan Marshall 2.vert). The Belgian authors also thank the University of Liège (Fonds Spéciaux pour la Recherche FSR C13/09) and the Fonds de Bay for their financial support. 


\section{References}

[1] N. Rey-Raap, J.A. Menéndez, A. Arenillas, RF xerogels with tailored porosity over the entire nanoscale, Micropor. Mesopor. Mater. 195 (2014) 266-275.

[2] N. Rey-Raap, J.A. Menéndez, A. Arenillas, Simultaneous adjustment of the main chemical variables to fine-tune the porosity of carbon xerogels, Carbon 78 (2014) 490499.

[3] A.M. Elkhatat, S.A. Al-Muhtaseb, Advances in tailoring resorcinol-formaldehyde organic and carbon gels, Adv. Mater. 23 (2011) 2887-2903.

[4] M.-L. Piedboeuf, F.L. Deschamps, A.F. Léonard, N. Job, Carbon xerogels as model materials: Towards a relationship between pore texture and electrochemical behavior as anodes for lithium-ion batteries, J. Mater. Sci. (2016).

[5] E.G. Calvo, F. Lufrano, P. Staiti, A. Brigandì, A. Arenillas, J.A. Menéndez, Optimizing the electrochemical performance of aqueous symmetric supercapacitors based on an activated carbon xerogel, J. Power Sources (2013).

[6] E.G. Calvo, N. Rey-Raap, A. Arenillas, J.A. Menéndez, The effect of the carbon surface chemistry and electrolyte $\mathrm{pH}$ on the energy storage of supercapacitors, RSC Adv. 4 (2014) 32398.

[7] J. Collins, G. Gourdin, M. Foster, D. Qu, Carbon surface functionalities and SEI formation during Li intercalation, Carbon 92 (2015) 193-244.

[8] K.-X. Wang, X.-H. Li, J.-S. Chen, Surface and Interface Engineering of Electrode Materials for Lithium-Ion Batteries, Adv. Mater. 27 (2015) 527-545.

[9] K.T. Lee, J.C. Lytle, N.S. Ergang, S.M. Oh, A. Stein, Synthesis and Rate Performance of Monolithic Macroporous Carbon Electrodes for Lithium-Ion Secondary Batteries, Adv. Funct. Mater. 15 (2005) 547-556.

[10] M.G. Sung, K. Hattori, S. Asai, Crystal alignment of graphite as a negative electrode material of the lithium-ion secondary batteries, Mater Design 30 (2009) 387390.

[11] A.D. Roberts, X. Li, H. Zhang, Porous carbon spheres and monoliths: morphology control, pore size tuning and their applications as Li-ion battery anode materials, Chem. Soc. Rev. 43 (2014) 4341-4356.

[12] D.L. Wood Iii, J. Li, C. Daniel, Prospects for reducing the processing cost of lithium ion batteries, J. Power Sources 275 (2015) 234-242.

[13] F. Béguin, F. Chevallier, C. Vix-Guterl, S. Saadallah, V. Bertagna, J.N. Rouzaud, E. Frackowiak, Correlation of the irreversible lithium capacity with the active surface area of modified carbons, Carbon 43 (2005) 2160-2167.

[14] M. Kakunuri, S. Vennamalla, C.S. Sharma, Synthesis of carbon xerogel nanoparticles by inverse emulsion polymerization of resorcinol-formaldehyde and their use as anode materials for lithium-ion battery, RSC Adv. 5 (2015) 4747-4753.

[15] A.M. Korsunsky, T. Sui, B. Song, Explicit formulae for the internal stress in spherical particles of active material within lithium ion battery cathodes during charging and discharging, Mater Design 69 (2015) 247-252.

[16] A. Pan, D. Liu, X. Zhou, B.B. Garcia, S. Liang, J. Liu, G. Cao, Enhanced lithiumion intercalation properties of coherent hydrous vanadium pentoxide-carbon cryogel nanocomposites, J. Power Sources 195 (2010) 3893-3899.

[17] S. Sun, C. Matei Ghimbeu, R. Janot, J.-M. Le Meins, A. Cassel, C. Davoisne, C. Masquelier, C. Vix-Guterl, One-pot synthesis of LiFePO4-carbon mesoporous composites for Li-ion batteries, Micropor. Mesopor. Mater. 198 (2014) 175-184. 
[18] S. Yoon, S. Lee, S. Kim, K.-W. Park, D. Cho, Y. Jeong, Carbon nanotube film anodes for flexible lithium ion batteries, J. Power Sources 279 (2015) 495-501.

[19] J.R. Dahn, T. Zheng, Y. Liu, J.S. Xue, Mechanisms for Lithium Insertion in Carbonaceous Materials, Science 270 (1995) 590-593.

[20] R. Alcántara, G.F. Ortiz, P. Lavela, J.L. Tirado, R. Stoyanova, E. Zhecheva, EPR, NMR, and Electrochemical Studies of Surface-Modified Carbon Microbeads, Chem. Mater. 18 (2006) 2293-2301.

[21] M. Winter, J.O. Besenhard, M.E. Spahr, P. Novák, Insertion Electrode Materials for Rechargeable Lithium Batteries, Adv. Mater. 10 (1998) 725-763.

[22] Y. Zhu, X. Xiang, E. Liu, Y. Wu, H. Xie, Z. Wu, Y. Tian, An activated microporous carbon prepared from phenol-melamine-formaldehyde resin for lithium ion battery anode, Mater. Res. Bull. 47 (2012) 2045-2050.

[23] N.P. Liu, J. Shen, D.Y. Guan, D. Liu, X.W. Zhou, Y.J. Li, Effect of carbon aerogel activation on electrode lithium insertion performance, Wuli Huaxue Xuebao Acta Phys. Chim. Sin. 29 (2013) 966-972.

[24] N. Job, R. Pirard, J. Marien, J.P. Pirard, Porous carbon xerogels with texture tailored by pH control during sol-gel process, Carbon 42 (2004) 619-628.

[25] X. Yang, H. Huang, G. Zhang, X. Li, D. Wu, R. Fu, Carbon aerogel with 3-D continuous skeleton and mesopore structure for lithium-ion batteries application, Mater. Chem. Phys. 149-150 (2015) 657-662.

[26] J. Li, B.L. Armstrong, C. Daniel, J. Kiggans, D.L. Wood Iii, Optimization of multicomponent aqueous suspensions of lithium iron phosphate (LiFePO4) nanoparticles and carbon black for lithium-ion battery cathodes, J. Colloid Interface Sci. 405 (2013) 118-124.

[27] X. Liu, S. Li, J. Mei, W.M. Lau, R. Mi, Y. Li, H. Liu, L. Liu, From melamineresorcinol-formaldehyde to nitrogen-doped carbon xerogels with micro- and meso-pores for lithium batteries, J Mater Chem A 2 (2014) 14429-14438.

[28] A.F. Léonard, C.J. Gommes, M.-L. Piedboeuf, J.-P. Pirard, N. Job, Rapid aqueous synthesis of ordered mesoporous carbons: Investigation of synthesis variables and application as anode materials for Li-ion batteries, Micropor. Mesopor. Mater. 195 (2014) 92-101.

[29] B. Zhang, S. Hao, D. Xiao, J. Wu, Y. Huang, Templated formation of porous Mn2O3 octahedra from Mn-MIL-100 for lithium-ion battery anode materials, Mater Design 98 (2016) 319-323.

[30] V.S. Nair, S. Sreejith, H. Joshi, Y. Zhao, A. West, S. Madhavi, The fabrication of LiMn2O4 and Na1.16V3O8 based full cell aqueous rechargeable battery to power portable wearable electronics devices, Mater Design 93 (2016) 291-296.

[31] W. Porcher, B. Lestriez, S. Jouanneau, D. Guyomard, Optimizing the surfactant for the aqueous processing of LiFePO4 composite electrodes, J. Power Sources 195 (2010) 2835-2843.

[32] J.M. Bermúdez, D. Beneroso, N. Rey-Raap, A. Arenillas, J.A. Menéndez, Energy consumption estimation in the scaling-up of microwave heating processes, Chem Eng Process 95 (2015) 1-8.

[33] K.S.W. Sing, Reporting physisorption data for gas/solid systems with special reference to the determination of surface area and porosity (Recommendations 1984), Pure Appl. Chem., 1985, p. 603.

[34] A. Lecloux, J.P. Pirard, The importance of standard isotherms in the analysis of adsorption isotherms for determining the porous texture of solids, J. Colloid Interface Sci. 70 (1979) 265-281. 
[35] M.M. Dubinin, Fundamentals of the theory of adsorption in micropores of carbon adsorbents: Characteristics of their adsorption properties and microporous structures, Carbon 27 (1989) 457-467. 